\title{
In-hospital outcomes of mechanical complications in acute myocardial infarction: Analysis from a nationwide Spanish database
}

\author{
Marcelo Sanmartín-Fernánde $z^{1}{ }^{\circledR}$, Sergio Raposeiras-Roubín ${ }^{2}$, \\ Manuel Anguita-Sánchez ${ }^{3}$, Francisco Marín , María García-Márquez ${ }^{5}$, \\ Cristina Fernández-Pérez ${ }^{5,6}$, José-Luis Bernal Sobrino ${ }^{5,7}$, \\ Francisco Javier Elola Somoza ${ }^{5}$, Héctor Bueno ${ }^{7}$, Ángel Cequier ${ }^{8}$ \\ ${ }^{1}$ Hospital Ramón y Cajal, CIBERCV, Madrid, Spain \\ ${ }^{2}$ Hospital Universitario Álvaro Cunqueiro, Vigo, Spain \\ ${ }^{3}$ Hospital Universitario Reina Sofía, Córdoba, Spain \\ ${ }^{4}$ Hospital Clínico Universitario Virgen de la Arrixaca, Universidad de Murcia, \\ IMIB-Arrixaca, CIBERCV, Murcia, Spain \\ ${ }^{5}$ Fundación Instituto para la Mejora de la Asistencia Sanitaria, Madrid, Spain \\ ${ }^{6}$ Servicio de Medicina Preventiva, Complejo Hospitalario Universitario De Santiago de Compostela, Spain \\ ${ }^{7}$ Hospital Universitario 12 de Octubre, Madrid, Spain \\ ${ }^{8}$ Hospital Universitario de Bellvitge, Universidad de Barcelona, IDIBELL, Hospitalet de L1, Spain
}

\begin{abstract}
Background: Mechanical complications represent an important cause of mortality in myocardial infarction (MI) patients. This is a nationwide study performed to evaluate possible changes in epidemiology or prognosis of these complications with current available strategies.

Methods: Information was obtained from the minimum basis data set of the Spanish National Health System, including all hospitalizations for acute myocardial infarction (AMI) from 2010 to 2015. Risk-standardized in-hospital mortality ratio was calculated using multilevel risk adjustment models.

Results: A total of 241,760 AMI episodes were analyzed, MI mechanical complications were observed in 842 patients: cardiac tamponade in 587, ventricular septal rupture in 126, and mitral regurgitation due to papillary muscle or chordae tendineae rupture in 155 (there was more than one complication in 21 patients). In-hospital mortality was 59.5\%. On multivariate adjustment, variables with significant impact on in-hospital mortality were: age (OR 1.06; 95\% CI 1.04-1.07; $p<0.001)$, ST-segment elevation AMI (OR 2.91; 95\% CI 1.88-4.5; $p<0.001$ ), cardiogenic shock (OR 2.35; 95\% CI 1.66-3.32; $p<0.001$ ), cardio-respiratory failure (OR 3.48; 95\% CI 2.37-5.09; $p<0.001$ ), and chronic obstructive pulmonary disease (OR 1.85; 95\% CI 1.07-3.20; $p<0.001$ ). No significant trends in risk-adjusted in-hospital mortality were detected (IRR 0.997; $p=0.109$ ). Cardiac intensive care unit availability and more experience with mechanical complications management were associated with lower adjusted mortality rates $(56.7 \pm 5.8$ vs. $60.1 \pm 4.5$; and $57 \pm 6.1$ vs. $59.9 \pm 5.6$, respectively; $p<0.001)$.

Conclusions: Mechanical complications occur in 3.5 per thousand AMI, with no significant trends to better survival over the past few years. Advanced age, cardiogenic shock and cardio-respiratory failure are the most important risk factors for in-hospital mortality. Higher experience and specialized cardiac intensive care units are associated with better outcomes. (Cardiol J 2021; 28, 4: 589-597)
\end{abstract}

Key words: myocardial infarction, mechanical complications, ventricular septal rupture, papillary muscle rupture, cardiac tamponade

Address for correspondence: Dr. Marcelo Sanmartín-Fernández, Cardiología Adultos, Hospital Ramón y Cajal, Carretera Colmenar Viejo 9100, 28034 - Madrid, Spain, tel: +34 616307157, e-mail: msanfer@me.com 


\section{Introduction}

Myocardial infarction-related mechanical complications (MI-MC) are uncommon but are frequently associated with severe morbidity and mortality. Presentation can vary from sudden cardiac death, typically related to pulseless electrical activity due to tamponade in free wall rupture, to asymptomatic tachycardia, with a new low-sternal murmur in some patients.

Data from different studies suggest that reperfusion therapy reduces the incidence of MI-MC when successful and performed in a timely manner $[1,2]$, but MI-MC still carry a very poor prognosis, despite important advancements in mechanical circulatory support [3-7]. The dismal outcomes of conservative therapy [8], leave surgical correction as a practically inevitable option with results depending on the clinical scenario, experience and appropriate timing [8-11]. Percutaneous closure of septal defects is a possible alternative to surgery, but are usually reserved for patients considered too ill to be operated on and with experience limited to a small number of centers and operators [12].

The past few years have witnessed a considerable growth of new imaging modalities and adjunctive therapies for the pre and postoperative support of MI-MC [3, 5, 6, 13-15]. However, most studies are limited to single-center experiences and by relatively small sample sizes. In addition, hospital characteristics may have an impact in the outcomes of patients with MI [16]. Accordingly, we performed a large nationwide retrospective study to analyze contemporary epidemiology of MI-MC, specifically examining recent trends in prevalence and to provide new insight into the impact of currently available supportive and corrective treatments on in-hospital mortality.

\section{Methods}

\section{Data source, population and design}

The present study is a retrospective longitudinal study using information provided by the minimum basis data set (MBDS) of the Spanish National Health System (SNHS). The MBDS is an administrative, anonymized database, with no information available linking variables to individual patients. Thus, no specific institutional review board authorization or patient informed consent documents were necessary [17]. All episodes with a principal discharge diagnosis of acute myocardial infarction (AMI) from January 2010 to December 2015 were included. The diagnosis of
AMI was identified by international classification of diseases $-9^{\text {th }}$ Revision Clinical modification (ICD-9-CM) codes $410 . * 1$ (410.71 for non-ST elevation AMI-NSTEMI-), MI-MC were identified by ICD-9-CM secondary codes 423.3 (cardiac tamponade), 429.71 (ventricular septal defect, acquired), 429.6 (rupture of papillary muscle), and 429.5 (rupture of chordae tendineae). Cardiac tamponade associated with cardiac surgery (codes 996.03, 996.70-79) or coronary interventions (998.2) were excluded.

Patients discharged alive at home within 1 day after admission, or with missing important demographics or principal diagnoses were excluded. To avoid duplications, transfers to other centers were only excluded if we were unable to identify the destination hospital. Secondary diagnoses were included in groups of risk factors as described by Pope et al. [18], updated each year by the Agency for Health Research and Quality. The quality of this MBDS for the study of acute coronary syndromes has been previously validated [19].

\section{Hospital characteristics}

Hospitals were qualified as having cardiac intensive care units (cICU) if they had: 1 ) a comprehensive critically-ill patient management capability, including those requiring invasive mechanical ventilation, and 2) administrative adscription of the cICU to the cardiology department.

\section{Statistical analysis}

Continuous variables were expressed as a mean (standard deviation) and categorical variables were expressed as numbers and rates. The Student t-test was used to compare two categories and ANOVA corrected by the Bonferroni test to compare three or more. Categorical variables were compared by the $\chi^{2}$ test or Fisher's exact test.

Since the probability of a patient dying is, indeed, a combination of their individual risk factors (case mix) and the quality of care provided (performance), the risk-standardized in-hospital mortality ratio (RSMR) was defined as the ratio between predicted and expected mortality, multiplied by the crude rate of mortality. RSMR was calculated using multilevel logistic regression models developed by the Medicare and Medicaid Service for risk adjustment, adapted to the structure of the MBDS database. Hospitals were modelled as random intercept considering both inter-hospital variability and clinical and demographic variables [20-22]. For the adjustment model, we considered only comorbidities with an odds ratio $(\mathrm{OR})>1.0$. The type of AMI (non-ST-segment elevation myocardial 


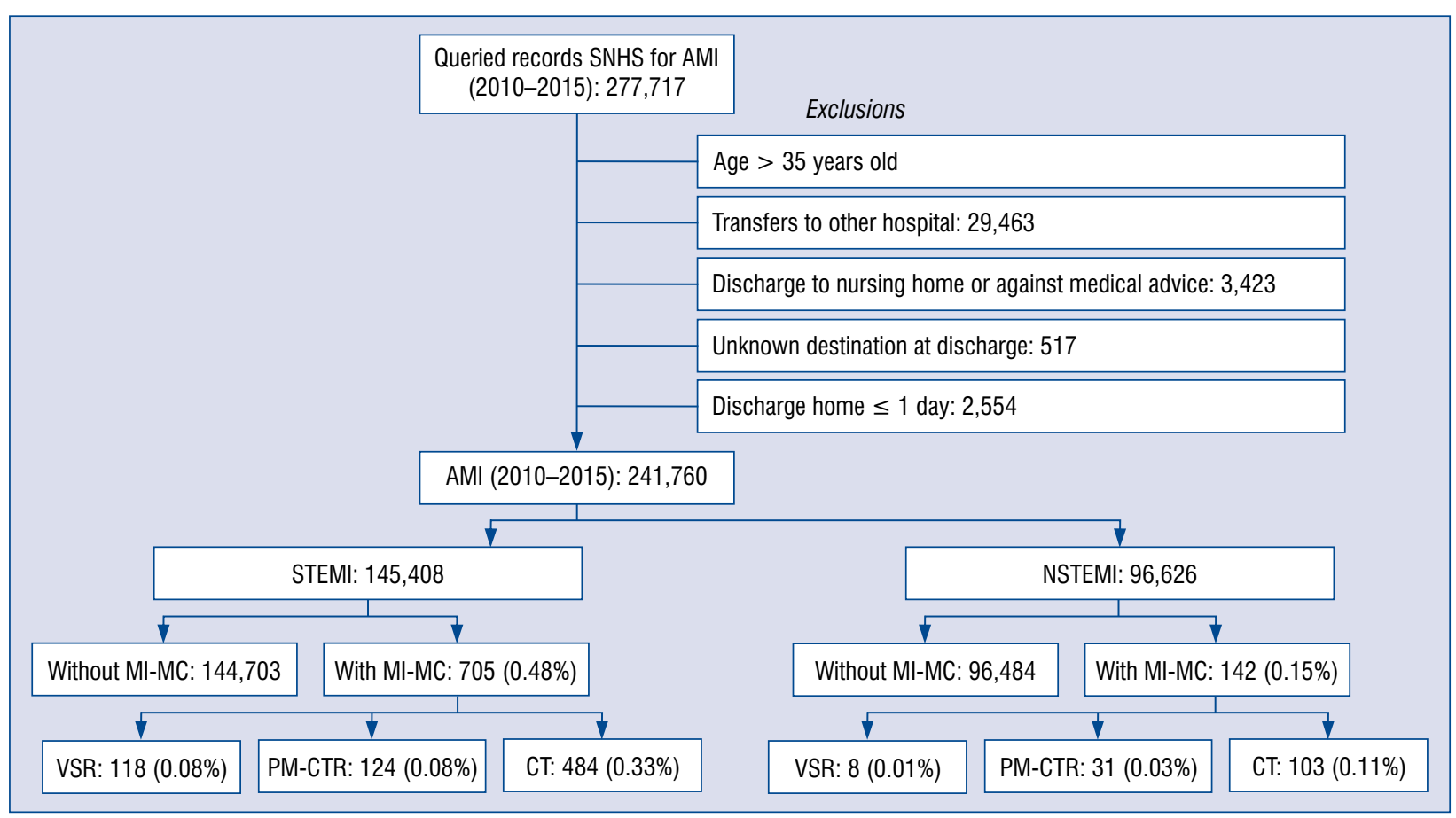

Figure 1. Flow chart of study population; SNHS - Spanish National Health System; AMI — acute myocardial infarction; STEMI - ST-segment elevation myocardial infarction; NSTEMI — non-ST-segment elevation myocardial infarction; MI-MC - myocardial infarction related mechanical complication; VSR - ventricular septal repture; PM-CTR — papillary muscle or chordae tendinae rupture; CT — cardiac tamponade.

infarction [NSTEMI] vs. ST-segment elevation myocardial infarction [STEMI]) was included in the adjustment models. All factors included in the final models and their coefficients were calculated from the present data. Levels of significance for selecting and eliminating risk factors were $p<0.05$ and $\mathrm{p} \geq 0.10$, respectively.

Calibration of models was assessed by calculating risk terciles of the in-hospital mortality observed and expected obtained by the logistic multilevel model. In order to evaluate the goodness of fit, a significant decrease in the statistical likelihood ratio test compared to the null model was tested. Discrimination was assessed by calculating the receiver operating characteristics curves and their corresponding area under the curve (AUROC).

Temporal trends for in-hospital mortality during the observed period were modelled using the Poisson regression analysis with year as the only independent variable. Incidence rate ratios (IRR) and their 95\% confidence intervals (95\% CI) were calculated. All statistical tests were two-sided. and the level of significance for $\mathrm{p}$-values was set at 0.05 . Statistical analysis was performed using STATA 13 and SPSS 21.0.

To discriminate between high and low volume centres a K means clustering algorithm was used, excluding hospitals with $<1$ cases of MC admissions in the study period. The mathematical model was developed with two-thirds of the dataset and validated with the remaining one third.

\section{Results}

\section{Prevalence of MI-MC}

A total 277,717 episodes of MI were identified in the MBDS during the study period (2010-2015). Figure 1 depicts the study flow-chart. A total of $13 \%$ of AMI episodes were excluded, the majority of which (10.6\%) for being discharged to other unidentified hospitals (Suppl. Table 1). From the 241,760 AMI selected for analysis, MI-MC were present in 842 patients (3.5 per thousand), and 25 patients had more than one MI-MC, resulting in a total number of mechanical complications of 863 . Cardiac tamponade unrelated to cardiac procedures was present in $67.4 \%$ of MI-MC cases $(\mathrm{n}=863)$. A ventricular septal defect was detected in $14.6 \%$ and mitral regurgitation in $17.9 \%$ (rupture of papillary muscle in $9.6 \%$ and rupture of chordae tendineae in 8.3\%). MI-MC incidence rate was higher in STEMI than NSTEMI ( 4.8 vs. 1.5 per thousand; $\mathrm{p}=0.002$ ).

There was a statistically significant trend to an increase of MI-MC throughout 2010-2015 (3.1 per 


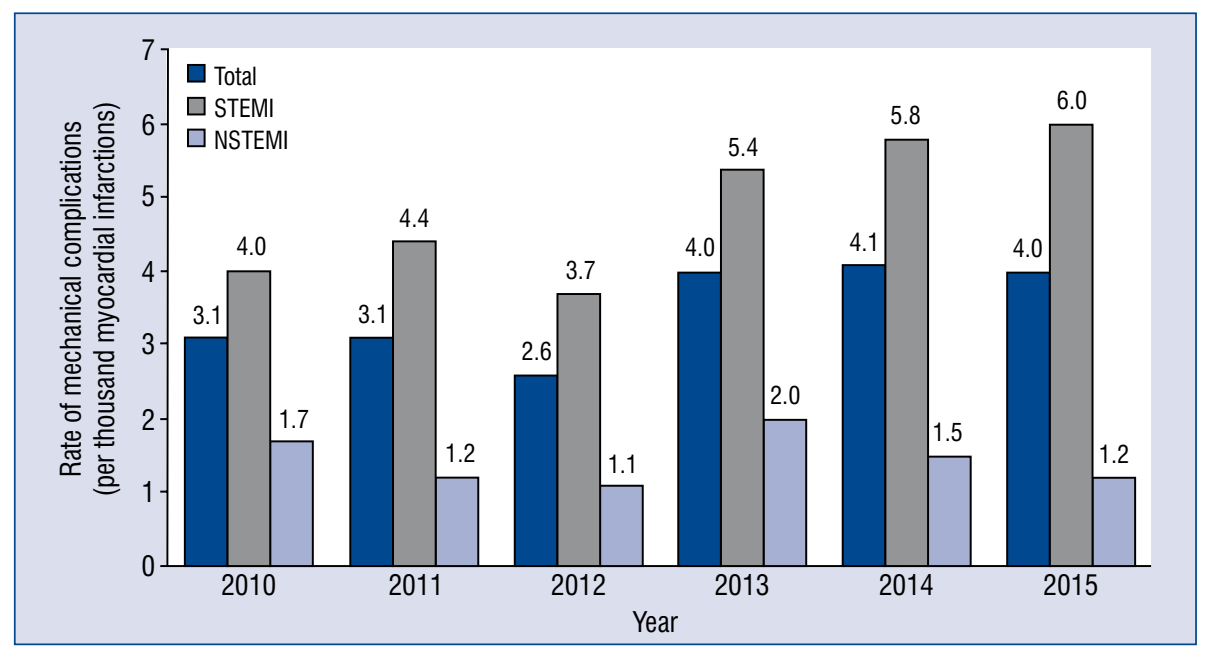

Figure 2. Trends in rates of mechanical complications in ST-segment elevation myocardial infarction (STEMI) and non-ST-segment elevation myocardial infarction (NSTEMI).

thousand AMI vs. 4.0 per thousand AMI; IRR 1.10; 95\% CI 1.07-1.13; $p<0.001$ ) with higher rates between 2013-2015 related with a higher incidence of MC in STEMI (Fig. 2). The trend towards MI-MC increase was due to cardiac tamponade (IRR 1.1, 95\% CI 1.04-1.14; $\mathrm{p}<0.001$ ), without significant changes in the other groups.

Differences between AMI patients with or without MI-MC are displayed in Table 1. MI-MC patients were older $(72.4 \pm 11$ vs. $68.6 \pm 14$; $\mathrm{p}<0.001$ ), with a higher prevalence of female sex (36.7\% vs. $30.3 \% ; \mathrm{p}<0.001$ ), and higher rates of cardiac failure, cardiogenic shock or cardiorespiratory failure and renal failure.

Risk factors associated with any MI-MC were older age, female sex, presentation with STEMI instead of NSTEMI, presence of valvular heart disease or chronic pulmonary disease and cardiogenic shock (Suppl. Table 2). The clinical characteristics associated with cardiac tamponade were: older age, presentation with STEMI instead of NSTEMI and cardiogenic shock (Suppl. Table 3). Risk factors for ventricular septal rupture (VSR) were: female sex (OR 1.86; 95\% CI 1.29-2.67; $\mathrm{p}<0.001$ ), prior MI (OR 1.63; 95\% CI 1.12-2.36; $\mathrm{p}=0.01)$, history of congestive heart failure (OR 2.23 ; 95\% CI 1.53-3.26; $\mathrm{p}<0.001)$, and presentation with STEMI (OR 6.29; 95\%CI 3.03-13.07; $\mathrm{p}<0.001$ ) and cardiogenic shock (HR 9.44; 95\% CI 6.34-14.05; $p<0.001$; Suppl. Table 4). Patients with papillary muscle or chordae tendinae rupture more frequently had a valvular heart disease, presentation with STEMI and cardiogenic shock (Suppl. Table 5).

\section{Management of MI-MC}

A percutaneous coronary intervention $(\mathrm{PCI})$ was performed in $55.7 \%$ of the patients with AMI-MC, a significantly lower rate compared with AMI without MI-MC (59.7\%; $\mathrm{p}=0.009)$. However, coronary artery bypass graft surgery $(\mathrm{CABG})$ procedures were more frequent in MI-MC (11.3 vs. 1.8; $\mathrm{p}<0.001)$. Along the study period, there was a higher trend to use of PCI (IRR 1.12; 95\% CI $1.08-1.17 ; \mathrm{p}<0.001)$ and CABG (IRR $1.16 ; 95 \% \mathrm{CI}$ $1.06-1.28 ; \mathrm{p}=0.002)$, but no significant changes in trends for mitral valve replacement or other major cardiac surgery (IRR 0.99; $\mathrm{p}=0.13$ and IRR 0.99; $\mathrm{p}=$ 0.05; respectively; Suppl. Fig. 1).

\section{In-hospital outcomes}

In-hospital crude mortality rate in MI-MC patients was $59.5 \%$, while mortality in patients without MI-MC was $9.6 \%$ ( $<0.001)$. The in-hospital mortality was $59.1 \%$ for cardiac tamponade (344 episodes), $66.7 \%$ for VSR (84 episodes), and $58.1 \%$ for papillary muscle/chordae rupture (90 episodes: $63.9 \%$ for papillary muscle rupture and $51.4 \%$ for rupture of chordae tendineae). The mortality was $81 \%$ when there were two MI-MC in the same AMI episode (17 episodes). There were no significant changes on in-hospital crude mortality rates during the 2010-2015 period (IRR 0.99; $\mathrm{p}=0.7$ ).

Table 2 shows the differences in risk factors between each MI-MC. Congestive heart failure, cardio-respiratory failure and shock, and renal failure were more frequent in VSR and mitral regurgitation-related complications, compared to the cardiac tamponade scenario. NSTEMI was rela- 
Table 1. Differences between acute myocardial infarction (MI) patients with and without mechanical complications (MC).

\begin{tabular}{|c|c|c|c|}
\hline Variables & $\begin{array}{l}\text { MI without MC } \\
(\mathrm{n}=240,918)\end{array}$ & $\begin{array}{l}\text { MI with MC } \\
(\mathrm{n}=842)\end{array}$ & $\mathbf{P}$ \\
\hline Age [years] & $68.6 \pm 14.0$ & $72.4 \pm 11.1$ & $<0.001$ \\
\hline Female sex & $30.3 \%$ & $36.7 \%$ & $<0.001$ \\
\hline \multicolumn{4}{|l|}{ Cardiovascular risk factors: } \\
\hline Smoking (ICD-9-CM code: V15.82) & $40.1 \%$ & $16.9 \%$ & $<0.001$ \\
\hline Hypertension (CC 95) & $49.2 \%$ & $43.6 \%$ & $<0.001$ \\
\hline Dyslipidemia (CC 25) & $15.0 \%$ & $9.5 \%$ & $<0.001$ \\
\hline Diabetes mellitus (CC 17-19. 123) & $32.4 \%$ & $23.0 \%$ & $<0.001$ \\
\hline \multicolumn{4}{|l|}{ Cardiovascular disease: } \\
\hline Peripheral artery disease* & $7.2 \%$ & $8.7 \%$ & 0.135 \\
\hline Prior myocardial infarction (ICD-9-CM code: 410.01 y 410.11 ) & $44.8 \%$ & $29.5 \%$ & $<0.001$ \\
\hline History of PCI (ICD-9-CM code: V45.82 y 996.72) & $12.0 \%$ & $7.6 \%$ & $<0.001$ \\
\hline Congestive heart failure (CC 85) & $22.6 \%$ & $34.4 \%$ & $<0.001$ \\
\hline Valvular heart disease (CC 106-108) & $7.1 \%$ & $8.2 \%$ & 0.251 \\
\hline \multicolumn{4}{|l|}{ Comorbidity: } \\
\hline Renal failure (CC 135-140) & $15.8 \%$ & $27.0 \%$ & $<0.001$ \\
\hline Chronic obstructive pulmonary disease (CC 111) & $7.5 \%$ & $9.7 \%$ & 0.015 \\
\hline Metastatic cancer, acute leukemia and other severe cancers (CC 8-9) & $1.2 \%$ & $0.6 \%$ & 0.118 \\
\hline \multicolumn{4}{|l|}{ Acute MI presentation: } \\
\hline STEMI (410.x1 except 410.71) & $60.1 \%$ & $83.7 \%$ & $<0.001$ \\
\hline Cardiogenic shock (ICD-9-CM code: 785.51) & $4.5 \%$ & $35.2 \%$ & $<0.001$ \\
\hline Cardio-respiratory failure and shock* (CC 84 except 785.51) & $9.1 \%$ & $29.0 \%$ & $<0.001$ \\
\hline Pneumonia (CC 114-116) & $2.3 \%$ & $4.6 \%$ & $<0.001$ \\
\hline Percutaneous coronary intervention & $57.9 \%$ & $55.7 \%$ & 0.009 \\
\hline Coronary artery bypass graft surgery & $1.8 \%$ & $11.3 \%$ & $<0.001$ \\
\hline
\end{tabular}

$\mathrm{PCl}$ - percutaneous coronary intervention; STEMI - ST-segment elevation myocardial infarction; CC - condition categories (Pope et al. [18]) *Peripheral artery disease (ICD-9-CM codes: 040.0. 440.0. 440.1. 440.20. 440.21. 440.22. 440.23. 440.24. 440.29. 440.30. 440.31. 440.32. 440.4. 441.00. 441.01. 441.01. 441.02. 441.03. 441.1. 441.2. 441.3. 441.4. 441.5. 441.6. 441.7. 441.9. 442.0. 442.1. 442.2. 442.3. 442.81. 442.82. 442.83. 442.84. 442.89. 442.9. 443.1. 443.21. 443.22. 443.23. 443.24. 443.29. 443.81. 443.82. 443.89. 443.9. 444.01. 444.09. 444.1. 444.21. 444.21. 444.22. 444.81. 444.89. 444.9. 445.01. 445.02. 445.81. 445.89. 447.1. 447.2. 447.3. 447.5. 447.6. 447.70. 447.71. 447.72. 447.73. 447.8. 447.9. 448.0. 557.0. 557.1. 557.9. 593.81. 785.4)

tively more frequent in the subgroup with rupture of papillary muscle or chordae tendineae.

In the multilevel risk adjustment model, several variables were independently associated with in-hospital mortality for AMI, including age, diabetes mellitus, cerebrovascular disease and STEMI presentation (Suppl. Table 6). Presentation of any MI-MC was also a strong predictor of in-hospital mortality (OR 9.16; 95\% CI 7.65-10.99; p < 0.001). Applying the AMI model to the population with MI-MC only four variables had a significant effect: age (OR 1.06; 95\% CI 1.04-1.07; p < 0.001), STEMI instead of NSTEMI (OR 2.90; 95\% CI 1.87-4.50; $\mathrm{p}<0.001)$, cardiogenic shock (OR 2.34; $95 \% \mathrm{CI}$ $1.66-3.31 ; \mathrm{p}<0.001)$, and cardio-respiratory failure (OR 3.48; 95\% CI 2.4-5.01; $\mathrm{p}<0.001$ )
(Table 3). This model showed a fair discriminative ability (AUROC 0.78; 95\% CI 0.75-0.80) and good calibration $(\mathrm{p}<0.001)$. PCI and cardiac surgery were independent risk-protective procedures for in-hospital mortality in MI-MC (OR 0.37; 95\% CI $0.27-0.50 ; \mathrm{p}<0.001$ and OR $0.43 ; 95 \%$ CI $0.30-0.62 ; \mathrm{p}<0.001$, respectively).

In-hospital mortality risk-adjustment models for each MI-MC showed significant differences in risk factors and their weight (Table 4). However, in all of them, cardiogenic shock and/or cardiorespiratory failure were strong predictors of inhospital mortality. Age was an independent risk factor only in VSR.

Risk-standardized in-hospital mortality ratio for MI-MC patients estimated with this model was 
Table 2. Differences among types of mechanical complications, baseline characteristics and comorbidities.

\begin{tabular}{|c|c|c|c|c|}
\hline Variables & $\begin{array}{c}\text { Cardiac } \\
\text { tamponade }\end{array}$ & $\begin{array}{l}\text { Ventricular } \\
\text { septal } \\
\text { rupture }\end{array}$ & $\begin{array}{c}\text { Papillary } \\
\text { muscle/chordae } \\
\text { tendinae rupture }\end{array}$ & Two MC \\
\hline $\mathrm{N}$ & 582 & 126 & 155 & 21 \\
\hline Age [years] & $71.78 \pm 10.9$ & $73.8 \pm 10.0$ & $73.0 \pm 12.3$ & $75.5 \pm 12.9^{*}$ \\
\hline Female sex & $35.2 \%$ & $46.0 \%$ & $34.19 \%$ & $33.3 \%$ \\
\hline \multicolumn{5}{|l|}{ Cardiovascular risk factors: } \\
\hline Smoking (ICD-9-CM code: V15.82) & $10.1 \%$ & $4.8 \%$ & $10.3 \%$ & $4.8 \%$ \\
\hline Hypertension (CC 95) & $44.5 \%$ & $43.7 \%$ & $38.1 \% *$ & $28.6 \%$ \\
\hline Dyslipidemia (CC 25) & $30.2 \%$ & $27.0 \%$ & $27.7 \% *$ & $23.8 \%$ \\
\hline Diabetes mellitus (CC 17-19. 123) & $24.4 \%$ & $24.6 \%$ & $16.8 \% *$ & $23.8 \%$ \\
\hline \multicolumn{5}{|l|}{ Cardiovascular disease: } \\
\hline Peripheral artery disease & $9.1 \%$ & $9.5 \%$ & $5.8 \%$ & $4.8 \%$ \\
\hline $\begin{array}{l}\text { Prior myocardial infarction } \\
\text { (ICD-9-CM code: } 410.01 \text { y } 410.11 \text { ) }\end{array}$ & $34.5 \%$ & $49.2 \% *$ & $14.2 \% *$ & 33.35 \\
\hline History of PCI (ICD-9-CM code: V45.82 y 996.72) & $7.6 \%$ & $7.9 \%$ & $6.5 \% *$ & $0.0 \%$ \\
\hline Congestive heart failure (CC 85) & $26.3 \% *$ & $47.6 \% *$ & $54.8 \% *$ & $38.1 \%$ \\
\hline \multicolumn{5}{|l|}{ Comorbidity: } \\
\hline Renal failure (CC 135-140) & $22.2 \% *$ & $41.3 \%$ & $32.3 \% *$ & $19.1 \%$ \\
\hline Chronic obstructive pulmonary disease (CC 111) & $10.5 \%$ & $10.3 \%$ & $5.8 \%$ & $4.8 \%$ \\
\hline $\begin{array}{l}\text { Metastatic cancer, acute leukemia and other } \\
\text { severe cancers (CC 8-9) }\end{array}$ & $0.7 \%$ & $0.0 \%$ & $0.7 \%$ & $0.0 \%$ \\
\hline $\begin{array}{l}\text { Dementia or other specified brain disorders } \\
\text { (CC 51-53) }\end{array}$ & $2.6 \%$ & $4.8 \%$ & $4.5 \%$ & $4.8 \%$ \\
\hline Trauma, other injuries (CC 166-168. 170-174) & $16.5 \% *$ & $15.1 \%$ & $6.5 \%$ & $4.8 \%$ \\
\hline \multicolumn{5}{|l|}{ Acute myocardial infarction presentation } \\
\hline NSTEMI (410.71) & $17.7 \%$ & $6.4 \% *$ & $20.0 \% *$ & $0.0 \% *$ \\
\hline Cardiogenic shock (ICD-9-CM code: 785.51) & $30.2 \% *$ & $47.6 \% *$ & $45.2 \% *$ & $47.6 \%$ \\
\hline Cardio-respiratory failure (CC 84 except 785.51) & $28.7 \%$ & 24.65 & $35.5 \% *$ & $42.9 \%$ \\
\hline Pneumonia (CC 114-116) & $5.0 \%$ & $2.4 \%$ & $4.5 \%$ & $0.0 \%$ \\
\hline
\end{tabular}

${ }^{*} \mathrm{p}<0.01 ; \mathrm{MC}$ - mechanical complications; $\mathrm{PCl}$ - percutaneous coronary intervention; NSTEMI — non ST-segment elevation myocardial infarction; CC - condition categories (Pope et al. [18])

$58.5 \%$ for the whole period 2010-2015, without significant changes along the studied period (IRR 0.997; 95\% CI 0.993-1; $\mathrm{p}=0.10$ ), while RSMR trend for MI without MC showed a steady decrease (IRR 0.97; 95\% CI 0.96-0.98; p < 0.001; Suppl. Fig. 2).

\section{Hospital characteristics and impact of availability of cICU}

The availability of cICU was associated with a lower RSMR $(56.5 \pm 5.7$ hospitals with cICU vs. $60.2 \pm 5.7$ without cICU; $p<0.001$; OR 0.60 ; 95\% CI 0.42-0.87; $\mathrm{p}=0.007)$. An association was also found between higher experience in MI-MC management (11 or more $\mathrm{MC}$ during the study period) and lower RSMR ( $57 \pm 6.1$ vs. $59.9 \pm 5.6$; $\mathrm{p}<0.001)$.

\section{Discussion}

The present study represents one of the largest series of patients with MI-MC. The main findings are: 1 ) the rates of MI-MC are 3.5 per thousand MI, similar to other contemporary series and with a small increase in the past few years [23, 24]; 2) the most frequent MI-MC is cardiac tamponade (2.4 per thousand), most likely related to free wall rupture, as PCI or CABG-related tamponade were excluded from this analysis, followed by mitral valve complications and VSR; 3) despite application of current adjunctive and corrective therapies, in-hospital mortality rates are still very high, varying from $59.1 \%$ and $58.1 \%$ in cardiac tamponade and papillary muscle/chordae tendineae rupture, respectively, to $63.9 \%$ in VSR; 4) age, heart failure 
Table 3. Multivariate analysis for in-hospital mortality of patients with acute myocardial infarction with mechanical complications.

\begin{tabular}{lccc}
\hline Risk factor & Odds ratio & $95 \% \mathrm{Cl}$ & $\mathbf{P}$ \\
\hline Age (18-44 years): & & & \\
$45-54$ & 1.57 & $0.19-3.81$ & 0.829 \\
$55-64$ & 1.04 & $0.17-3.05$ & 0.657 \\
$65-74$ & 1.77 & $0.25-4.25$ & 0.964 \\
$75-84$ & 3.68 & $0.59-9.92$ & 0.219 \\
$85-94$ & 8.19 & $1.24-24.54$ & 0.025 \\
$\geq 95$ & 19.94 & $0.00-0.00$ & 0.981 \\
STEMI (410.*1 except 410.71) & 2.91 & $1.94-4.49$ & $<0.001$ \\
Cardiogenic shock (ICD-9-CM code: 785.51) & 2.35 & $1.83-3.62$ & $<0.001$ \\
Cardio-respiratory failure (\%) (CC 84 except 785.51) & 3.48 & $2.10-4.37$ & $<0.001$ \\
Chronic obstructive pulmonary disease (CC 111) & 1.85 & $1.07-3.19$ & 0.027 \\
Percutaneous coronary intervention* & 0.37 & $0.27-0.50$ & $<0.001$ \\
Other major surgery* & 0.43 & $0.30-0.62$ & $<0.001$ \\
\hline
\end{tabular}

*Effect of the interventions on the risk-adjustment basal model; $\mathrm{Cl}$ — confidence interval; NSTEMI — non-ST-segment elevation myocardial infarction; CC — condition categories (Pope et al. [18])

Table 4. Variables independently associated with in-hospital, all-cause mortality adjusted by risk in a multilevel logistic regression model for different mechanical complications.

\begin{tabular}{|c|c|c|c|c|c|c|}
\hline \multirow[t]{2}{*}{ Risk factor } & \multicolumn{2}{|r|}{ CT } & \multicolumn{2}{|r|}{ VSR } & \multicolumn{2}{|c|}{$\mathrm{PM} / \mathrm{CT}$ rupture } \\
\hline & OR & $95 \% \mathrm{Cl}$ & OR & $95 \% \mathrm{Cl}$ & OR & $95 \% \mathrm{Cl}$ \\
\hline STEMI $\left(410 .^{*} 1\right.$, except 410.71$)$ & 2.43 & $1.52-4.00$ & & & & \\
\hline Cardiogenic shock (ICD-9-CM code: 785.51) & & & 9.97 & $3.35-29.69$ & 4.68 & $1.89-11.62$ \\
\hline Cardio-respiratory failure and shock (CC 84 except 785.51) & 3.09 & $2.01-4.73$ & & & 3.35 & $1.38-8.11$ \\
\hline Acute myocardial infarction (CC 86) & 2.18 & $1.18-4.05$ & & & & \\
\hline
\end{tabular}

CT — cardiac tamponade; VSR — ventricular septal rupture; $\mathrm{PM} / \mathrm{CT}$ - papillary muscle or chordae tendineae rupture; OR — odds ratio; $\mathrm{Cl}$ confidence interval; STEMI - ST-elevation myocardial infarction; CC — condition category (Pope et al. [18])

and cardiogenic shock are strong predictors of inhospital mortality; 5) hospitals with specialized cardiac critical care units, managed by Cardiology Departments, present better results.

The current results differ from a large database in the United States, in which MI-MC occurred in $0.27 \%$ of all STEMI patients, and $0.06 \%$ in NSTEMI, with a lower presence of free-wall rupture, $(0.01 \%$, compared to $0.21 \%$ for ventricular septal defects and $0.05 \%$ for papillary muscle rupture) [24]. Importantly, the study by Elbadawi et al. [24] used the ICD-9 code 553.9 for "free-wall rupture". This code matches with "hernia of unspecified site without mention of obstruction or gangrene" and is not used in the Spanish MBDS for the description of post-MI free-wall rupture. Despite the important limitation of including tamponade as a clinical correlate of free-wall rupture, the present estimations are more in accordance with our clinical experience and other reports [1]. However, the two databases provide similar results regarding a relatively stable prevalence of MI-MC over the past few years and the steady high mortality rates.

Therapeutic options for MI-MC apparently do not impact survival, despite advances in peripheral mechanical circulatory support and various corrective techniques [1, 11, 15, 24]. Surgical techniques for the repair of the infarcted tissue of ventricular septal defects have been stable over the past decades and the relatively low prevalence has limited surgeons' experience to a small number of cases per year, even in high-volume centres. Percutaneous closure of ventricular septal defects appears feasible, but greatly challenged by the anatomical complexity of the defects and carries a high risk of recurrences due to the friable borders of the infarcted septum [12]. 
Unfortunately, the possible contribution of mechanical support manoeuvres, especially venoarterial extracorporeal membrane oxygenation (VA-ECMO) or percutaneous VSR repair could not be addressed in this study due to difficulties with non-uniform codification within the MDBS. Advanced age, cardio-respiratory failure and cardiogenic shock were the main independent predictors of total mortality in this study.

Current guidelines recommend centralizing the care of patients with cardiogenic shock in highly specialized centres [25], since this approach has been consistently associated with better outcomes in this clinical setting [26]. In this study, the availability of an cICU and higher experience in the management of these patients were both associated with higher survival rates, probably reflecting the effect of specialized training and expertise in the diagnosis and management of MI with complications.

\section{Limitations of the study}

This study has a number of limitations that have to be considered. First, this is a retrospective analysis. The use of administrative records to estimate outcomes has been widely applied to research on health service outcomes [27, 28]. Second, $10.6 \%$ of episodes were not included in the study population for being discharged to other acute general hospitals. This elimination process was necessary to avoid duplications and because inhospital outcomes for these patients were not available. Third, as mentioned, the diagnosis of free wall rupture is not clearly specified in ICD-9 codes and therefore cardiac tamponade was used as probably infarct-related, after excluding those clearly caused by invasive procedures. We believe this variable served as a correlate of free-wall rupture, but it is not a substitute for autopsy or surgically-proven rupture, because another cause could be epistenocardic or inflammatory pericarditis. However, the mortality rates observed in this study (59.1\%) are not typical of post-infarction pericarditis. In addition, a certain degree of misdiagnosis could not be excluded, as some patients may present with sudden death or electromechanical dissociation without imaging or autopsy confirmation of cardiac tamponade. With respect to the adjustment models, there are confounding factors that are impossible to identify, but may have a significant impact. The presence of cardio-respiratory failure and shock is under-estimated in MBDS. The secondary diagnoses employed as risk-adjustment variables may correspond to conditions that are present on admission or to complications that may occasionally reflect inadequate treatment. Nevertheless, the models used in this study compare favourably against models published elsewhere regarding predictive capacity [29]. Finally, limited information on detailed clinical characteristics such as time between beginning of symptoms and primary PCI and between culprit vessel revascularization and diagnosis of MI-MC precluded more detailed analysis of predictors of different complications and outcomes.

\section{Future perspectives}

Much work needs to be done in reducing mortality in this complex scenario. There is an urgent need to explore the role of different circulatory support modalities, especially in VSR, and the impact of emerging interventional techniques, ideally in a prospective, randomized design.

\section{Conclusions}

Myocardial infarction-mechanical complications occur in 3.5 per thousand MIs and are more typically related to STEMI, with a slight increase in prevalence over the past years. Cardiac tamponade is the most frequent presentation, accounting for $69 \%$ of all MI-MC. These conditions still carry a very high mortality risk, that has not been changing over the past few years. Advanced age and cardiogenic shock are the most important risk factors for in-hospital mortality. Availability of highly specialised and experienced CICU favourably impact in-hospital outcomes in this complex scenario.

\section{Data availability}

The data underlying this article were provided by the Ministry of Health by permission. Data will be shared on request to the corresponding author with the permission of the Ministry of Health.

\section{Acknowledgements}

The authors thank the Spanish Ministry of Health, for the help provided to the Spanish Society of Cardiology to develop the RECALCAR study. Special gratitude to the General Directorate of Public Health, Quality, and Innovation.

\section{Funding}

The work for this paper was funded by an unconditional grant from Laboratorios Menarini (RECALCAR Project).

Conflict of interest: None declared 


\section{References}

1. Puerto E, Viana-Tejedor A, Martínez-Sellés M, et al. Temporal trends in mechanical complications of acute myocardial infarction in the elderly. J Am Coll Cardiol. 2018; 72(9): 959-966, doi: 10.1016/j.jacc.2018.06.031, indexed in Pubmed: 30139440.

2. Figueras J, Alcalde O, Barrabés JA, et al. Changes in hospital mortality rates in 425 patients with acute ST-elevation myocardial infarction and cardiac rupture over a 30 -year period. Circulation. 2008; 118(25): 2783-2789, doi: 10.1161/CIRCULATIONAHA.108.776690, indexed in Pubmed: 19064683.

3. Chen L, Chen K, Ni H, et al. Veno-Arterial ECMO in the setting of post-infarct ventricular septal defect: a bridge to surgical repair. Heart Lung Circ. 2018; 27(6): 771-772, doi: 10.1016/j. hlc.2017.06.731, indexed in Pubmed: 29706181.

4. Obadia B, Théron A, Gariboldi V, et al. Extracorporeal membrane oxygenation as a bridge to surgery for ischemic papillary muscle rupture. J Thorac Cardiovasc Surg. 2014; 147(6): e82-e84, doi: 10.1016/j.jtcvs.2014.03.003, indexed in Pubmed: 24680391.

5. Giuliani L, Archilletti F, Rossi S, et al. Impella CP and VenoArterial Extracorporeal Membrane Oxygenator as a sequential add-on combination circulatory support in ST-segment elevation myocardial infarction complicated by cardiogenic shock. Cardiovasc Revasc Med. 2019; 20(11S): 60-62, doi: 10.1016/j.carrev.2019.08.002, indexed in Pubmed: 31488363.

6. Wernly B, Seelmaier C, Leistner D, et al. Mechanical circulatory support with Impella versus intra-aortic balloon pump or medical treatment in cardiogenic shock-a critical appraisal of current data. Clin Res Cardiol. 2019; 108(11): 1249-1257, doi: 10.1007/ s00392-019-01458-2, indexed in Pubmed: 30900010.

7. Schäfer A, Werner N, Westenfeld R, et al. Clinical scenarios for use of transvalvular microaxial pumps in acute heart failure and cardiogenic shock - A European experienced users working group opinion. Int J Cardiol. 2019; 291: 96-104, doi: 10.1016/j. ijcard.2019.05.044, indexed in Pubmed: 31155332.

8. Lemery R, Smith HC, Giuliani ER, et al. Prognosis in rupture of the ventricular septum after acute myocardial infarction and role of early surgical intervention. Am J Cardiol. 1992; 70(2): 147-151, doi: 10.1016/0002-9149(92)91266-7, indexed in Pubmed: 1626498.

9. Arnaoutakis GJ, Zhao Y, George TJ, et al. Surgical repair of ventricular septal defect after myocardial infarction: outcomes from the Society of Thoracic Surgeons National Database. Ann Thorac Surg. 2012; 94(2): 436-43; discussion 443, doi: 10.1016/j. athoracsur.2012.04.020, indexed in Pubmed: 22626761.

10. Li H, Zhang S, Yu M, et al. Profile and outcomes of surgical treatment for ventricular septal rupture in patients with shock. Ann Thorac Surg. 2019; 108(4): 1127-1132, doi: 10.1016/j.athoracsur.2019.03.101, indexed in Pubmed: 31075249.

11. Goldsweig AM, Wang Y, Forrest JK, et al. Ventricular septal rupture complicating acute myocardial infarction: Incidence, treatment, and outcomes among medicare beneficiaries 1999-2014. Catheter Cardiovasc Interv. 2018; 92(6): 1104-1115, doi: 10.1002/ccd.27576, indexed in Pubmed: 29513365.

12. Sabiniewicz R, Huczek Z, Zbroński K, et al. Percutaneous closure of post-infarction ventricular septal defects-an over decade-long experience. J Interv Cardiol. 2017; 30(1): 63-71, doi: 10.1111/ joic.12367, indexed in Pubmed: 28078714.

13. Davidsen C, Packer EJS, Løland KH, et al. Impella use in acute myocardial infarction complicated by cardiogenic shock and cardiac arrest: Analysis of 10 years registry data. Resuscitation. 2019; 140: 178-184, doi: 10.1016/j.resuscitation.2019.04.022, indexed in Pubmed: 31009694.

14. Ostadal P, Rokyta R, Kruger A, et al. Extra corporeal membrane oxygenation in the therapy of cardiogenic shock (ECMO-CS): rationale and design of the multicenter randomized trial. Eur J Heart Fail. 2017; 19 Suppl 2: 124-127, doi: 10.1002/ejhf.857, indexed in Pubmed: 28470919.
15. Hernández Jd. Mechanical Complications in Elderly Patients With Myocardial Infarction. J Am Coll Cardiol. 2018; 72(9): 967969, doi: 10.1016/j.jacc.2018.06.032.

16. Bertomeu V, Cequier Á, Bernal JL, et al. In-hospital mortality due to acute myocardial infarction. relevance of type of hospital and care provided. RECALCAR study. Rev Esp Cardiol (Engl Ed). 2013; 66(12): 935-942, doi: 10.1016/j.rec.2013.06.006, indexed in Pubmed: 24774106.

17. Registro de altas de hospitalización: CMBD del Sistema Nacional de Salud. Glosario de términos y definiciones. Portal estadístico SNS [actualizado Sep 2016]. p. 5-6.

18. Pope GC, Ellis RP, Ash AS, et al. Diagnostic cost group hierarchical condition category models for Medicare risk adjustment. Health Economics Research Inc, Waltham, MA 2000.

19. Bernal JL, Barrabés JA, Íñiguez A, et al. Clinical and administrative data on the research of acute coronary syndrome in spain. Minimum basic data set validity. Rev Esp Cardiol (Engl Ed). 2019; 72(1): 56-62, doi: 10.1016/j.rec.2018.01.026, indexed in Pubmed: 29747944.

20. Shahian DM, Normand SL, Torchiana DF, et al. Cardiac surgery report cards: comprehensive review and statistical critique. Ann Thorac Surg. 2001; 72(6): 2155-2168, doi: 10.1016/s00034975(01)03222-2, indexed in Pubmed: 11789828.

21. Normand S-LT, Glickman ME, Gatsonis CA. Statistical methods for profiling providers of medical care: issues and applications. J Am Statistical Association. 1997; 92: 803-814.

22. Goldstein H, Spiegelhalter D. League tables and their limitations: statistical issues in comparisons of institutional performance. J Royal Statistical Society. Series A (Statistics in Society). 1996; 159(3): 385, doi: 10.2307/2983325.

23. French JK, Hellkamp AS, Armstrong PW, et al. Mechanical complications after percutaneous coronary intervention in ST-elevation myocardial infarction (from APEX-AMI). Am J Cardiol. 2010; 105(1): 59-63, doi: 10.1016/j.amjcard.2009.08.653, indexed in Pubmed: 20102891.

24. Elbadawi A, Elgendy IY, Mahmoud K, et al. Temporal trends and outcomes of mechanical complications in patients with acute myocardial infarction. JACC Cardiovasc Interv. 2019; 12(18): 1825-1836, doi: 10.1016/j.jcin.2019.04.039, indexed in Pubmed: 31537282.

25. Ponikowski P, Voors AA, Anker SD, et al. 2016 ESC Guidelines for the diagnosis and treatment of acute and chronic heart failure: The Task Force for the diagnosis and treatment of acute and chronic heart failure of the European Society of Cardiology (ESC)Developed with the special contribution of the Heart Failure Association (HFA) of the ESC. Eur Heart J. 2016; 37(27): 2129-2200, doi: 10.1093/eurheartj/ehw128, indexed in Pubmed: 27206819.

26. Shaefi S, O'Gara B, Kociol RD, et al. Effect of cardiogenic shock hospital volume on mortality in patients with cardiogenic shock. J Am Heart Assoc. 2015; 4(1): e001462, doi: 10.1161/ JAHA.114.001462, indexed in Pubmed: 25559014.

27. van Walraven C, Jennings A, Taljaard M, et al. Incidence of potentially avoidable urgent readmissions and their relation to allcause urgent readmissions. CMAJ. 2011; 183(14): E1067-E1072, doi: 10.1503/cmaj.110400, indexed in Pubmed: 21859870.

28. Krumholz HM, Wang Y, Mattera JA, et al. An administrative claims model suitable for profiling hospital performance based on 30-day mortality rates among patients with an acute myocardial infarction. Circulation. 2006; 113(13): 1683-1692, doi: 10.1161/CIRCULATIONAHA.105.611186, indexed in Pubmed: 16549637.

29. Sendra Gu, Sarría-Santamera A. Iñigo Martínez J. Desarrollo de un modelo de ajuste por el riesgo para el infarto agudo de miocardio en España: comparación con el modelo de charlson y el modelo ICES. Aplicaciones para medir resultados asistenciales. Revista española de salud pública. 2006; 80: 665-677. 